\title{
4 Anger, Comradeship and Age-set Exogamy among Maasai: an Elaboration of Alliance Theory ${ }^{1}$
}

The enthusiasm of Maasai for every loving detail of their culture displays a flamboyant confidence in their way of life, and this is echoed in the wider reputation of the Maasai throughout the region. There is an exuberant pride in togetherness that unites men and women of all ages. To be a Maasai is to share in this sense of comradeship, ranging from membership of a particular grouping to their society at large.

However, this euphoric display is tinged with an underlying anger that suggests fundamental shortcomings to this ideal. The Maasai reputation as a highly egalitarian society is an age-set ideal among moran, but it overlooks gross inequalities that are at the roots of their anger. Within the family, there are great differences in wealth and fortune. Between age-sets, there are rivalries that can build up to heated disputes. Above all, the rigid straitjacket that confines all women to a life of bondage displays the supreme inequality. Comradeship at one level is bolstered by inequality and a shared anger at another. These may be viewed as the opposite sides of a coin that has been shaped by the cultural premise of being Maasai.

\subsection{Comradeship and Anger among Women}

Women's dancing is a highlight of their generally confined existence in which for the most part they are dispersed and tied down by domestic responsibilities under the heavy-handed control of their husbands. When gathered together in dance, this may reveal an element of play and of rivalry between them, but above all a sense of comradeship that can verge on an intimidating challenge to the dominance of the elders.

The most common venue for women's dancing is a local wedding ceremony. As they process to the celebration in small groups, they chant in a prayer to God for children with gleefully obscene allusions to their own sexuality coupled with pointed insults regarding the peccadilloes of elders in general as dirty old men. Their song is an inviting call to other women, promising a measure of temporary freedom from domestic drudgery. This sets the tone for the dances that follow once they are

1 The sections on women's dancing in this chapter were previously published in Spencer, P. (ed.), 1985, Society and the Dance. Cambridge University Press, Cambridge. (pp. 157-61). I am grateful to Cambridge University Press for their permission to reproduce these sections here. Some other parts of the chapter derive from an unpublished paper that was submitted in 2002 for a conference on 'Friendship, Descent, and Alliance' at the Max Planck Institute of Social Anthropology, Halle, and this is due to be published in its original form by Berghahn Books. 
gathered together, marking out an inviolable domain that firmly excludes all males as the principal butt of their joking.

During the brief period of an unusually good wet season, the women's dancing may become an everyday event, and then it can acquire a new significance. During such a season, a vague rumour may spread among the women of some malignant presence affecting their fertility. The pressure may then build up to marshal their numbers and perform their fertility dances. They may process for a few days or even (it is claimed) weeks, dancing from village to village, coercing elders for food and gifts, blessing them and their wives when they comply, but with the power to vent their anger and in effect curse any man who refuses them or prevents his wife from joining them. Away from the village, no man would want to cross their path. If they catch him in the bush, they may mob, manhandle, and even rape him in the belief that this could cure their barrenness. ${ }^{2}$

The collective power of women during the wet season is most formidable when they sense that their fertility has been put at risk by sexual misconduct that violates the avoidance between 'fathers' and 'daughters'. This extends to intercourse after any pregnancy has been established, for it could bring a husband or lover into sexual contact with his unborn daughter (or son). It is believed that a series of miscarriages suffered by any woman implies that she has violated this prohibition, posing a threat to the fertility of all women. At first it may be just speculation, but in the wet season when domestic pressures are eased, the rumour may build up with a welling anger that spreads within the region. This triggers a mass gathering of angry women, dancing and calling on those who are not pregnant to join in mobbing the homestead of the suspect wife to safeguard their own fertility. They catch hold of the victim, beat her and slice skin off her forehead, scarring her face for life. They wreck her hut and slaughter a fat ox from her family herd. Then they cover her head and shoulders with chime, which mixes with her blood, and drive her from her home in order to absolve her. If they can catch her husband or some lover who is suspected of violating the avoidance of 'daughters', then he too will be beaten by the mob.

The women are united in their anger against a threat to womankind in general. Their sense of comradeship is one of belligerence against unseen forces, while the taunts in their songs are directed against the elders at large. On their sorties, they make explicit the parallel with moran who are angry and united in battle as comrades and defy anyone to stand in their way, calling on one another to join the gathering. The aim of moran is to protect their herds when they are threatened, or to add to them

2 Samburu women refer to similar dances as ntorosi, which is identical to the Maasai term for a vow among diehard moran to outshine all others in battle against their enemies. Among Samburu women, there is a similar element of anger and coercion implicit in their ritualized confrontations with elders and the general premise that gifts to the dancers bring God's blessing. 
when they undertake a raid. The aim of a women's mobbing is to protect their right to bear children by defeating malignant forces that have invaded their domain. As they express it:

mobbing women : preserving fertility and gaining babies

:: fighting moran : preserving herds and gaining cattle

Elders remain aloof from such a mobbing, apart from displaying their support for the gathering by preparing the ox's carcase for the women's meat feast, for it is held that the women do not have the finesse to cook the ox for themselves. With this feasting, the women are pacified and the perceived threat to their fertility is lifted. The victim is taught a lesson, and they disperse to their homes, singing as they go. If any elder dares to punish his wife for taking part in such an activity, he risks provoking a further mobbing by angry women, who may beat him if they can catch him and slaughter his favourite ox - and leave the carcase to rot.

This can be illustrated by four reported incidents. In the first, a woman was mobbed after a series of miscarriages, and she and her lover were blamed for continuing to have sex during her pregnancies. As the mob approached his village, her husband drove out a particularly fine ox to offer them before they seized it from his herd. In exonerating himself from any blame, he was spared. In a second instance, an elder suspected of raping the daughter of an age mate (and hence 'of his age-set') tried to protect his favourite ox from a women's mobbing. They caught him and beat him so viciously that he was maimed for life. In a third, another elder was suspected of incest with his own daughter. When he heard that women were collecting together to mob him, he migrated with his family and herd to another tribal section. Other elders were convinced of his innocence, but this was no protection once the rumour had become established and the women had made up their minds. In a fourth, a habitual drunkard was criticized by other elders for pawing an age-set daughter on several occasions. In their gossip, his age mates strongly disapproved of his behaviour, but they felt that this was a matter for women to settle rather than for them to impose an age-set curse. They assumed that it was only a matter of time before rumours would spread and the anger of women would lead to a mobbing.

\subsection{Seasonal Influences on Interaction}

The intriguing feature of women's dancing and mobbing is the condition under which their anger or even a rumour of misfortune spreads, threatening the one affliction that they all dread - barrenness. This is the height of the wet season, which brings a whole range of disturbances after months of drought and hunger. The expected reaction is one of relief; but there is also a surplus of nervous energy as people turn their attention from the rigours and anxieties of day to day survival to broader issues. Elders are freer 
to go visiting, staying away from home, calling in cattle debts, broking marriages, and so on. The rain can cover the tracks of stolen cattle, and hence this is a time when outbursts of raiding and counter-raiding for cattle may be expected between tribal sections, and the moran too have a role to fulfil as the traditional defenders of their herds. The Maasai also recognise that the rains can bring a certain irritability and an unsettling feeling that all is not quite well despite the good times. My own personal impression was of a spate of requests for medicine for headaches and vaguely defined disorders, especially from women. It was as if people were disoriented by the sudden change of fortune, and they did not immediately adjust to this. Unlike the dry season, which builds up slowly and relentlessly, giving Maasai time to adjust themselves mentally and physically, the onset of the wet season has an immediate impact. Milk is not at first plentiful, but it is assured; the long trek for water involving both men (for the cattle) and women (for domestic use) is ended; options for migration open out.

For the women, however, there are no new options, and they remain subservient. They are in no way consulted by their husbands during their flurry of visiting, which may concern the marriages of their daughters, the introduction of a new co-wife and potential rival into their homes, or giving away cattle previously allocated to a wife. These are men's affair and there is no call to involve their wives. The gulf of inequality that divides the sexes seems to widen. At least during the prolonged dry season, with the survival of the family and herd at stake, there is a spirit of cooperation; but this spirit does not appear to carry over to the easier times of the wet season.

The rumour of a threat to women's reproductive powers at this time, even among those who already have children, threatens their whole future, which hinges on bearing children. It may be a rumour that arouses their anger because of a woman's indiscretions during pregnancy or more vaguely a rumour of some mystical threat to their fertility that expresses a more diffuse sense of anger. If it is to be explained at a symbolic level, the credibility of this rumour seems to indicate a loss of confidence among women in their domestic status. Within each household this loss of confidence may appear at first as an idiosyncratic domestic issue. Repeated over a whole region at this time, and a sense of crisis gathers momentum, suggesting a breakdown of normal communication and a widening of the gulf between the sexes. The rumour appears as an apt expression of this crisis, raising the whole issue to a supernatural plane and challenging the women to recover from their inertia and to assert their rightful role as the reproducers of Maasai society, rather as moran have a rightful role in asserting themselves against any threat to their cattle herds.

As the rumour gains credibility, it builds up to a force that legitimises the women's response. From their situation of semi-isolation and domestic discord, their dancing or mustering as a mob bring large numbers of women together, where in militant mood they act in concord. Their consciousness awakened beyond their domestic subservience, the notion of a direct contact with God, and the widespread compliance they demand from the elders, seem to revive their spirits and give them renewed confidence to re-establish themselves with greater self-respect in their own 
households. The women's dancing and mobbing, in other words, build up their confidence and this is perceived as an interaction with cosmic forces that lie beyond the power of elders to hold them in total subservience.

Seen from this point of view, the women's dancing is more than a mere safety valve for domestic claustrophobia, and the women are more than passive invalids needing to pamper one another. They are mobilised as a social class, fully conscious of their position and temporarily asserting their right to an independent arena from which even the elders cower. Ritual reversal and a notion of impending ill-fortune may thus be linked to ritual rebellion in a system of oppression. Through a ritualised expostulation, a slump in morale among women is reversed. Moreover it is not just the women who are purified, but the whole atmosphere in this reassertion of the importance of womanhood. Their dancing has a brief reality of its own, which readjusts the balance of power between the sexes, and is felt to bring with it a diffuse blessing on their fertility and on the birth of future generations.

\subsection{Group Indulgence and the Restrictions of the Age-set System among Men}

As previously noted, the Maasai area is divided into sixteen 'tribal' sections, and within any section there are typically three or four manyata villages, sited strategically to defend their territories. These are set up at the beginning of each new age-set when novice moran claim possession of the privileges of moranhood. Once they have secured these privileges, small bands of novice moran scour their territory to recruit for their manyata, and they take along their mothers. Their fathers are expected to comply with this and to want their sons to develop within the discipline of the manyata. Occasionally, a father may try to make a reasoned plea for dispensation, claiming that he needs his wife for domestic reasons and his morani son to help with the herd. This will not stop other moran from snatching away the woman, and her morani son will follow. If the father tries to put his weight as an elder behind his request, he will be forcibly held down by the other moran. Exceptions to the rule of manyata recruitment are made on their merit - if there is good reason to avoid this duty - but it is the local body of novice moran who make the final decision. Elders (and fathers in particular) are highly respected, and even feared for their power to curse. But in the context of manyata recruitment of their sons and senior wives, they are obliged to respect the physical assertiveness of the body of moran.

With their public role focused on building up their manyata as the supreme privilege, the moran are the most flamboyant and ritualized sector of Maasai society. At the same time, the years that they spend together at the manyata are a critical period for inculcating the bonds of loyalty that characterize the age-set system. The glamour of moranhood centres on the manyata and it is there that they cultivate and parade an ethos of sharing. They shun any form of self-indulgence in public and should always 
seek the company of other moran. They cannot drink milk by themselves and, because of other food prohibitions, this means that they must go hungry on any morning or evening when they happen to be alone, until they have found the company of at least one other morani to offer them milk.

Away from the family dominated by the father, manyata moran build up a rich store of experiences that they continue to share anecdotally in later life. These extend throughout the territory defended by the manyata, and even to diplomatic visits to neighbouring manyat and beyond. Intense bonds of friendship between age mates grow out of their years at their manyata. This is characterized by an excessive display of 'group indulgence', opposed to any suggestion of self-interest. This male age-bonding is expected to form the basis of friendship for the rest of their lives. An extreme expression of friendship would occur when two moran shared a joint pledge in battle. They would defend one another to the end, and if one was killed, the other would risk his life to lay out the corpse properly. However, the notion of such 'friendship' should not imply any sense of pairing or cliquishness, excluding others. Thus 'comradeship' would better express the ideal of the manyata, with the emphasis on unity and sharing. In a similar vein, no morani should claim exclusive access to any girl who is his lover, for this would be to display jealousy towards his peers' right to share. Inevitably, some friendships may be closer than others, but such intimacy should not be displayed in public: no other morani should be excluded from their company. Exclusive pairing between lovers or between moran is anathema to the manyata. It is disloyal and a denial of sharing.

After an extended period, the manyata is disbanded. This is followed by a significant step towards elderhood when each morani is made to drink milk offered by an elder and not by an age mate. Moran who have performed this ceremony say that they have difficulty in swallowing the milk, and for some time afterwards they lose their appetite and age visibly. They may even seek out age mates informally to share milk as they did in the past; but they no longer enjoy the experience and find that the spell of moranhood has been broken. Whereas the ideal of equality among moran was enacted through sharing company, milk, girlfriends, and anything else that could be shared, this ideal is compromised when they become elders.

This is a time when they begin to marry, around the age of thirty, and build up their families and herds. As elders they continue to share food and the sexuality of their wives with their age mates. As fathers whose children may have been (visibly) begotten by an age mate, they should show a delight and gratitude that these sexual liaisons have produced offspring that are an asset to the family, regardless of paternity. They should show no jealousy or discrimination towards these children, supporting the ideal of age-set unity above any notion of personal affront. However, the sharing - even the attractions of sex - is of consumables. Age mates share milk, meat and the marital bed, but their cattle and children remain their own as individuals. As against the egalitarian ideal of moranhood, the independence of elders creates differences in wealth, and dedicated herding practices coupled with luck can increase these 
differences. While this is softened by the continued emphasis on the strength of age-set bonds, it is consumption and not ownership that is shared.

After they have married, age mates do not necessarily live together in the same village, and of course they too move around. But there are always age-mates in the vicinity, and it is with these that they tend to look for company in their leisure time, which increases as their sons become old enough to manage the family herd alone. The very fact of their nomadism brings age mates constantly into touch with one another; and so do feasts on various ritual occasions, when they again share meat together. As dispersed elders, they are scrupulous in maintaining bonds within the age-set as a whole, but the fact that they acquire the power to curse with elderhood gives this bond a sinister edge. The belief in this curse lays bare the frustrations elders experience as they age and as the egalitarian restrictions of moranhood give way to the competitive opportunities of building up their own households and herds.

The contradiction between egalitarian ideals and unequal shares of fortune may relate to a haunting concern that casts a shadow over elders' ritual feasting when each age-set sits together as a separate group of jovial comrades. This is a belief that jealous sorcerers could be lurking in the bush nearby, bent on sowing havoc among the feasters by interfering with their ritual. At a time when age-set loyalties prevail in their sharing and self-indulgent cravings are formally banished, it is as if these emotions re-emerge as shadowy projections of their malcontented other selves, jealously aware of the unfairness of the inequalities.

While jealousy contradicts the ethos of Maasai society, anger plays a legitimate role. The elders' power to curse is held to emanate from the gripping anger following a slight by someone who is expected to show respect. It is maintained that in learning how to control and direct this anger, an elder's curse has a potent effect, even if it is just felt rather than uttered. As individuals, elders may try to stifle their anger by responding diplomatically to some slight by a younger man, and they would retain general respect for their moderation. As an age-set, any anger that is shared among age mates does not require diplomacy. A curse by his age-set leaves a man totally isolated from his age peers.

At any elders' meeting that involves all age-sets on some local issue, the aim is to arrive as a unanimous agreement. If just one individual refuses to comply with this aim, the only sanction against him is through members of his age-set. He is not obliged to submit to a majority decision by elders of other age-sets, but he cannot defy pressure from within his own. Even if just two age mates make a reasonable request to a third, then they act as representatives of the age-set and their request has a coercive power. Men are bound by their age-set. In the view of women and younger men, elders are self-indulgent and mean hypocrites, who put their own selfish interests above those of their families and have a terrible curse over younger people. But the view from within the age-set is that loyalty to age mates is still the highest virtue, and this reveals a strong sense of group-indulgence, which lasts for the rest of their lives. 
As members of an age-set die off in old age, the age-set loses its vitality, but the notion of age-set comradeship persists to the end.

In addition to the sinister power of the curse that characterizes elderhood, there is a further ambiguity that undermines the idyllic image of the peer-group in later life. The activities of moran are centred on the territory that their manyata is pledged to defend. This comprises just one part of the total tribal section, whereas elders migrate freely with their homesteads across the whole of this section, and very occasionally even across the border into a neighbouring section for a while. This brings these elders into regular contact with age mates whom they do not know so well, because they had been moran at different manyat. Over time, they may come to know one another better, especially when they find themselves allied politically against other age-sets at formal gatherings. But they do not share the same manyata experience and this leads to a more formal relationship that tends to stress the element of age-set obligation and duty. The relationship lacks the spontaneity of comradeship stemming from a shared youth. Thus when elders visit their age mates, the host is obliged to vacate his wife's hut for the night, in effect offering his wife - if she consents. This is a punctilious obligation, but a visiting friend from manyata days may invite the host to remain in his hut, so that they can continue to share one another's company overnight. So long as such lapses are in the spirit of age-set unity, no harm is done, but it is a very private arrangement. If an elder were to avoid this obligation in any other circumstance, then his age mates could raid his village, kill a prized ox for a feast, and force themselves on his wife. The host is then expected to show his gratitude, for this would be undertaken with a view to quelling their anger and avoiding their age-set curse. Worst of all would be if a visiting age mate from another tribal section is denied full hospitality in any way, for his resentment would have the automatic effect of an age-set curse. The stranger who is also an age mate is one of the most threatening anomalies of Maasai elderhood, and observing age-set obligations and generosity are more than just scrupulous, they become almost obsessive.

This reveals a spectrum of relations within the age-set. The closest lifelong friendships tend to relate back to the manyata experience and age-set obligations as elders may be relaxed in a spirit of total trust. At the opposite extreme, obligations towards the stranger age-mate from across the section border become excessively rigid with the bleak spectre of an age-set curse. As a stranger, he is dehumanized and represents the faceless age-set at large.

\subsection{Marriage Bonds and the Fundamental Premise of the Maasai Age-set System}

Sexuality among the Maasai is characterized by institutionalized adultery with the wives of age mates and discreet adultery between men and women in general. Weak clan exogamy and the absence of strong corporate lineages correspond to a lack of 
serious concern over sexual encounters between distant kin. Intercourse between a distant 'brother' and 'sister' arouses a sense of ridicule rather than horror; seducing the wife of a 'father' is thought to be dangerous because of his potent curse if he finds out, but not because it is ritually dangerous in itself. Admittedly incest with a close 'sister' or 'mother' would be repugnant, but at the same time almost inconceivable.

However any suggestion of incest between an elder and a woman who may be classified as a 'daughter' does evoke horror. Even a hint of intimacy between a man and a 'daughter': would arouse gossip and risk his being manhandled by an angry mob of mature women. Because daughters of his age mates ('age-set daughters') are more numerous than any other category of 'daughter', this avoidance is an especially sensitive issue. Any younger women that he meets for the first time could be an age-set daughter, and he should be circumspect in even addressing her until he has established her paternity.

To appreciate the significance of this particular relationship, it has to be borne in mind that a Maasai woman is uniquely linked to her father's age-set. As a 'daughter', she can have only one father, whereas as a mother or sister, she can have sons or brothers in two or even three different age-sets. Similarly, elders of an age-set can assert exclusive possession over a category of marriageable women - their 'daughters' - whereas they have no such claim over their 'sisters' or 'mothers', who are also 'sisters' and 'mothers' of other age-sets. The term age-set exogamy may be coined in relation to marrying 'daughters' only to men of other age-sets, corresponding to the notion of clan exogamy in relation to clan 'sisters' among other peoples, including the Samburu.

In a curious way, this is reminiscent of Lévi-Strauss's treatment of incest and exogamy. This argued that to show less than complete sexual avoidance of the 'sisters' of ones own descent group threatens the system of alliances between lineages through intermarriage: it is the exchange of women between lineages within the wider society that forms the fundamental bonds and the basis of social solidarity.

In this way, Lévi-Strauss viewed the horror of incest as an expression of outraged public morality reflecting these close bonds. This was an elaboration of Tylor's earlier suggestion that extended families were too small to survive without exogamy - they faced the practical alternative between 'marrying out and being killed out' - and of Mauss's notion that gift exchange (in this case of women) underpinned society as a moral force. ${ }^{3}$

Lévi-Strauss's theory has been treated as an odd episode of anthropological history and inferior to his more mature structuralism that followed. He has been accused of conflating incest avoidance and exogamy, and to this extent of confusing sex with marriage. ${ }^{4}$ However, a point I would note is that the Maasai quite explicitly

3 Lévi-Strauss 1969: 62; Tylor 1889; Mauss 1924

4 Leach 1970: 103 
link these together, and they are particularly unprudish on the issue of marriage and sex, except that a man must not marry any woman whom he would avoid as a 'daughter', and this involves a considerable proportion of all women.

Lévi-Strauss regarded the elaboration of his theory concerning prescriptive forms of marriage as largely irrelevant to African societies, which only rarely have precisely defined rules of exogamy. However, among the Maasai one appears to have an oblique confirmation of this theory. The pattern of age-set exogamy corresponds exactly with the intense horror of incest with age-set daughters. One may also note the unilateral aspect of the Maasai system. Brides are consistently married downwards - from older fathers to younger husbands. In age-set terms, this may be compared with LéviStrauss's tantalizing model of matrilateral cross-cousin marriage. (Whereas a delayed exchange of brides, echoing his model of patrilateral cross-cousin marriage, would imply marrying age-set daughters upwards to older as well as to younger sons-in-law, and this has no parallel in the Maasai age-set system.)

This leads one to attempt to transpose Lévi-Strauss's argument from the bonds that unite corporate descent groups into the wider kinship system, to bonds that unite age-sets into the wider age-set system. The theory has to be modified to adapt it to the Maasai context. It is the strict avoidance of each 'daughter' by all members of her father's age-set that structures the system of marriage. They are the wife-givers, and her husband's age-set are the wife-receivers, sharing certain rights in her hut and sexuality.

Basically the argument would run as follows. Unlike lineages, age-sets are not self-perpetuating groups. They dwindle into old age, and the flow of 'daughters' is towards more junior age-sets. This provides a basis from which the more senior agesets can exercise power over their juniors, demanding respect as potential fathersin-law with the power to withhold their 'daughters'. Given the competition for wives between age-sets and the strong bonds of comradeship within each age-set, one may ask: what if age mates were allowed to marry each other's daughters, consolidating age-set bonds by bestowing these 'daughters' as wives? ${ }^{5}$ A system of exchange of 'daughters' within the age-set would then be possible. In the spirit of age-set sharing and loyalty, a father could be under irresistible pressure from age mates to give them priority over suitors from junior age-sets. To prefer some other suitor could be construed as an act of disloyalty to his own age-set, and it could even provoke an implicit age-set curse. Such a request would be dangerous to refuse. This would then encourage 'in-marriage' and 'daughters' would accrue as wives of the most senior agesets instead of being handed downwards.

In such a system, older men would accumulate large harems while mature bachelors would find it even harder to marry in the foreseeable future. Deprived of the opportunity to marry, this could even drive older moran to rebel against the elders'

5 Cf. Lévi-Strauss 1969: 41 
regime, reminiscent of the change-over of generation-sets in northern Uganda on the one hand and Freud's scenario in Totem and Taboo on the other. ${ }^{6}$

The practice of age-set exogamy ensures that this situation does not arise, and indeed it provides a bridging in a system that precipitates perpetual rivalry between adjacent age-sets. Paraphrasing Tylor, each Maasai age-set is faced with the simple practical alternative between marrying 'daughters' out (and down) and families dying out. In forbidding 'daughters' to one another as age mates, elders are ensuring the succession of their families as fathers. Following through Lévi-Strauss's argument suggests that the horror of incest with a 'daughter' is an indication of the extent to which age-set exogamy provides the bedrock of social morality. The gifts of women cement the bonds that unite different age-sets into a more comprehensive age system.

Bearing in mind the jostling on the age ladder, the tensions between age-sets should not be underestimated. The ideal of loyalty within an age-set corresponds to an undercurrent of rivalry with adjacent age-sets, contradicting the outward display of respect for older men. Young elders, whose wives have been repeatedly seduced by adulterous moran, are especially angry. They may convene as an age-set and threaten a curse over any 'daughter' who is given away in marriage to any morani. This threatens to break down any marriage negotiations between the two families. But the threat cannot be sustained, and elders of more senior age-sets try to mediate, encouraging the junior elders to accept compensation without loss of face and to lift their threat. The adulterous moran then find themselves obliged to offer very substantial gifts of cattle and other commodities to the offended elders. The asymmetrical system of alliance is restored, and the age-set of moran have transcended a serious obstacle on their path towards elderhood. The junior elders then become their 'fathers-in-law', a popular Maasai term for the next age-set up. Possibly over one quarter of all marriages are in fact with daughters of the senior adjacent age-set.

Thus, through the marriages of daughters, one has the first rapprochement between the two age-sets since the time when they were first confronting one another over the privileges of moranhood, and later over the adulterous activities of moran. With elderhood, regardless of subsequent struggles, these two age-sets are related through their daughters-wives, and this provides a permanent link between them with all that this implies for affinal relations.

This avoidance also has implications for the maturation of young men. Before the entry of moran into elderhood, they display a casual abandon in their treatment of women. They tease the girls as playthings, they regard young wives as potential objects of their adulterous opportunism, and when they too marry as young elders, they treat their own wives in a very high-handed manner and continue to show an interest in the young wives of other age-sets and even in unmarried girls. It is only when they begin to marry and their wives bear them daughters that for the first time in

6 Dyson-Hudson 1966: 155-206; Freud 1950: 141-2) 
their lives they encounter a category of unrelated women that they should avoid - their age-set daughters. This is a significant stage in their domestication, and it builds up over the years to the point when these daughters start to marry. Now, when they meet a young attractive woman whom they do not know, they cannot automatically assess her bedworthiness. She just might be a 'daughter' and they should avert their gaze, or at least address her distantly until they can ascertain that she is not a 'daughter'. With the acquisition of 'daughters', the notion of respect acquires a new dimension, and with it the formal reserve that characterises elderhood.

\subsection{Conclusion: Elders as Controllers and Women as Custodians of the Age-set System}

Among the Maasai, moran and women are confined to their roles in cultural straitjackets. For moran, this confined role is idolized and ends with their promotion to elderhood. For women their role as wives is a binding commitment from which they are only partially released in old age, as widows under the protection and control of their sons. For both sexes, their cultural confinement has a bearing on their simmering anger. Anger is an aspect of the ethos of moranhood. As warriors, they are expected to be primed to defend their herds and to go on raids in a spirit of controlled anger that has no mystical consequences. Following from the discipline of moranhood, an aspect of their maturation as elders is that they must learn to control their anger, directing the cosmic forces that are now felt to emanate from the grip of this anger. This contrasts with the implications of women's anger during their fertility dances and mobbings. Their anger is held to be beyond control. In responding to mystical forces that threaten their fertility, their mass anger is in danger of triggering random destruction.

The ideal of age-set loyalty persists into elderhood, and this is fanned by disruptive rivalries between age-sets, leading to a problem of continuity over time. In this respect, Lévi-Strauss's alliance theory has an unexpected relevance. With only shallow corporate lineages, marriage bonds among the Maasai might seem irrelevant to this theory. However, once the theory has been transformed to match a social organization based on age rather than descent, this turns out to be an impressive vindication of the theory. The intense rivalries between age-sets are held in check by a unilateral network of bonds through marriage and the transition of women from being 'daughters' of a more senior age-set to becoming 'wives' of a more junior. The way in which the horror of incest is expressed is consistent with the social solidarity of the 'connubium' of age-sets. This involves a type of hypogamy, with the avoided daughters married downwards to younger men, who in order to qualify as eligible suitors are obliged to show respect for their seniors. 'Age-set exogamy' ensures the marriage market for moran as they settle down, which is essential for the perpetuation of the age-set system. One is not therefore just concerned with the morality underlying 
social solidarity among men of all ages, but also with the reproduction of this morality that runs in parallel with the biological reproduction of society and hence with the reproduction of the age-set system itself.

The avoidance of age-set daughters is very common among neighbours of the Maasai, such as the Samburu but also beyond Maa. However, the pattern is obscured by clan exogamy, which is altogether more pronounced elsewhere and with it a more extensive range of sexual avoidances. In these other societies, the avoidance of 'daughters' does not stand out as a category that is in a class of its own, whereas the Maasai case appears to be pronounced, because it is so clear-cut.

It is the women, without age-sets of their own, who form a vital link between men's age-sets through their marriages. Frustrated by the restrictions of their domestic subservience, women's fertility dances accompany songs with ribald allegations against the elders at large and obscene references to their own sexuality. These amount even to quasi-sacrilegious jibes against their own avoided fathers. Further to the extreme of asserting their independence, women take the law into their own hands as infuriated viragoes when they retaliate against any elder who violates a 'daughter'. Such a violation is felt to release mystical forces that threaten women's fertility generally. They convene as a rampaging angry mob, bent on up-ending the normal social order. The implication is that by matching cosmic chaos and venting their anger in a collective reversal of normal behaviour, they will restore their fertility. That cheating elders and especially the most culpable are the ultimate butt of women's outbursts links the hypocrisies of elders in general with a sense of cosmic chaos, just as responsible behaviour by the collectivity of elders in normal times is assumed to be in harmony with the charm of a cosmic order that protects Maasai society.

The elders are apprehensive of women collecting together to dance and rampage, but they are powerless to intervene. They can only hold their wives in subjection up to the point at which women's anger finds expression collectively and becomes an unstoppable force. This endows women with a formidable role that in the final resort serves to maintain the age-set system at the heart of the men's domain. Ultimately, it is their wives who are the guardians of the moral code associated with sensitive sexual avoidances. As such, angry women are bastions of a regime that holds them in subjection. 